\title{
JOGO CAZUMBÁ: UMA PROPOSTA DE JOGO DE TABULEIRO PARA O ENSINO DO BUMBA MEU BOI
}

Gisele Reis Correa Saraiva, Mestra

Universidade Federal do Maranhão - UFMA

gisarco41@gmail.com

Cláudia Nayanne Gaspar Sousa, Graduada

Universidade Federal do Maranhão - UFMA

claudia.ngaspar@gmail.com

Resumo: O presente trabalho intitulado "JOGO CAZUMBÁ: uma proposta de jogo de tabuleiro para o ensino do Bumba Meu Boi", refere-se a uma pesquisa teórico e prática, a partir de uma monografia de conclusão do curso de Design (Sousa, 2015) com base na cultura maranhense. O estado do Maranhão é reconhecido no Brasil pela sua diversidade cultural. No que se refere às manifestações folclóricas, o Bumba Meu Boi é o principal representante. No entanto, percebe- se que poucas pessoas na capital do Estado, São Luís, não conhecem com propriedade a história dos movimentos culturais. Por isso, a presente pesquisa tem como objetivo desenvolver um jogo de tabuleiro lúdico pedagógico, abordando a temática do Bumba Meu Boi, destinado ao público infantil, no intuito de estimular o conhecimento sobre da cultura popular local. Para o desenvolvimento do projeto utilizou-se a metodologia de Munari (2008), bem como se realizou pesquisas bibliográficas e de campo, resultando em um jogo de tabuleiro que irá proporcionar benefícios aos usuários, devido a suas características de funcionalidade usual e estética, tornando-se uma importante ferramenta no aprendizado da cultura popular maranhense.

Palavras-chave: Design, Cultura, Bumba Meu Boi, Jogo.

ABSTRACT: This paper named: "CAZUMBÁ GAME: a proposal for board game to the teaching of Bumba Meu Boi", refers to a theoretical and practical research, from a monograph completion of design course (SOUZA, 2015), based on maranhense culture. Maranhão is recognized in Brazil for its cultural diversity. With regard to folklore, the Bumba Meu Boi is the main representative. However, it can be seen that few people in the state capital, Saint Louis, know the history of cultural movements. Therefore, this research aims develop an educational playful board game addressing the issue of Bumba Meu Boi, for children public, in order to encourage knowledge of the local popular culture. To develop the project, the Munari (2008) methodology was used, as well bibliographical and field research has been done, resulting in a board game that will provide benefits to 
users, due to its usual functionality and aesthetic characteristics, becoming an important tool on learning of maranhense popular culture.

Keywords: Design, Culture, Bumba Meu Boi, Game.

\section{INTRODUÇÃO}

O modo de brincar expressa a maneira como a criança reflete, ordena, desorganiza, e reconstrói o seu mundo. Segundo Kishimoto (2011), o brinquedo propõe um mundo imaginário a criança. Assim, é importante a presença do lúdico nas brincadeiras infantis, pois é uma forma eficaz de envolvê- las nas atividades, logo será sua maneira de trabalhar, refletir e descobrir o mundo. De acordo com Friedmann (1996), é fundamental tomar consciência de que a atividade lúdica infantil fornece informações elementares a respeito da criança: suas emoções, a forma como interage com seus colegas, seu desempenho físico - motor, seu estágio de desenvolvimento, seu nível linguístico, sua formação moral. Sendo assim, o jogo implica para a criança muito mais do que o simples ato de brincar, possibilitando também a sua comunicação com o mundo ao seu redor, ou seja, sua cultura.

Segundo Eagleton (2011), cultura é uma das palavras mais nobres, porém complexa da Língua Portuguesa. Etimologicamente significa "cultivo", mas sua raiz latina é "colere", que tanto pode significar cultivar como "habitar", "adorar" ou "proteger". Edward Taylor sintetizou estes termos num único vocábulo no inglês culture - e ampliou o significado incluindo conhecimentos, crenças, arte, moral, leis, costumes ou qualquer outra capacidade ou hábitos adquiridos pelo homem como membro de uma sociedade (LARAIA, 2004). A cultura aparece como herança social, abrangendo todas as práticas humanas, formando conjunto de bens materiais e imateriais que retratam o cotidiano, representando o produto da dinâmica cultural, onde cada grupo humano apresenta particularidades que os diferencia e o identificam diante de um todo, pelo modo como vivem, como se relacionam e o que constroem (CORREA, 2010).

O Brasil possui uma cultura riquíssima. O Estado do Maranhão, em particular, é reconhecido pela diversidade cultural principalmente no que se refere às manifestações folclóricas, tendo o Bumba Meu Boi como principal representante. $\mathrm{Na}$ brincadeira popular o Bumba Meu Boi trata-se de um auto dramático, por meio do teatro, da música e da dança. No Maranhão, os grupos de boi são divididos em cinco principais ritmos, estilos ou sotaques: de Matraca ou da Ilha, de Zabumba, Pindaré ou da Baixada, Cururupu ou Costa - de - mão e de Orquestra.

E o que se percebe, apesar da capital do Estado do Maranhão contar com inúmeras riquezas arquitetônicas, ter o título de Patrimônio Cultural da Humanidade concedido pela Organização das Nações Unidas para a Educação, a Ciência e a Cultura (UNESCO) e ser caldeirão de manifestações culturais, poucos maranhenses conhecem a fundo a história de cada movimento cultural presente no Maranhão (SANTOS, 2012, at.).

Diante da falta de informações sobre a riqueza das tradições da cultura maranhense no ensino tanto na educação infantil, como também na adolescência e na fase adulta, buscou-se nesta pesquisa desenvolver um projeto de produto, 
especificamente, um jogo de tabuleiro sobre o Bumba Meu Boi, traduzindo seus valores e ideais, destacando seus principais personagens, sotaques (ritmos), e instrumentos, constituindo clareza, flexibilidade, originalidade e empenho com a visão da cultura popular, voltado principalmente para o público infantil.

A proposta do jogo, que tem como título Jogo Cazumbá (SOUSA, 2015), é destinado ao público infantil com idade a partir de 8 anos de idade, pois segundo o Pacto Nacional pela Alfabetização na Idade Certa - PNAIC (BRASIL, 2012), a partir dos 8 anos de idade a criança já deve ter domínio sobre compreensão e fluência de leitura. Buscando assim, introduzir a cultura popular maranhense nas brincadeiras infantis, contribuindo para sua valorização.

O projeto do Jogo Cazumbá (SOUSA, 2015) visa na vida das crianças, estimular o conhecimento da tradição da cultura popular maranhense do Bumba Meu Boi, por isso, apresenta-se de forma lúdica pretendendo fazer com que as crianças aprendam com prazer, alegria e entretenimento a sua cultura popular. Outro aspecto aqui considerado, é que embora o jogo Cazumbá retrate sobre o Bumba Meu Boi do Maranhão pode também ser jogado por um público de outro estado, já que o Maranhão faz parte dessa grande cultura rica e diversa do território brasileiro.

\section{A CRIANÇA E O JOGO}

A infância é a fase da vida onde somos crianças, por onde se inicia o aprendizado e as descobertas.

Para Silveira (2000), a vivência da infância muda conforme os paradigmas do contexto histórico, dessa forma, pensar na infância significa buscar algumas evidências articuladas à família e à escola, importância da criança dentro de uma comunidade, enfatizando que esta varia conforme o período em que ela está inserida, seus direitos e interferências.

Em uma determinada fase da infância, a criança desenvolve suas emoções e explora sua fantasia, que aparece em muitas atividades principalmente através do brincar, proporcionando assim oportunidades de interação nas brincadeiras que realiza no seu cotidiano com outras crianças, adultos e principalmente com si mesma.

Brincando elas se apropriam criativamente de formas, de ação social tipicamente humana e de práticas sociais específicas dos grupos aos quais pertencem. Assim aprendem sobre si mesmas e sobre o mundo em que vivem (RODRIGUES, 2009).

A necessidade da criança brincar ativa sua criatividade, estimula sua capacidade de respeitar as regras de uma simples brincadeira, levando a aprendizagem para a vida. Como ressalta Machado (2003, p.37) “brincar é também um grande canal para o aprendizado, senão o único canal para verdadeiros processos cognitivos.

Segundo Vygotsky (2007, p.118): o brinquedo cria na criança uma nova forma de desejos. Ensina-a a desejar, relacionando seus desejos a um "eu" fictício, ao seu papel no jogo e suas regras.

O jogo é uma forma de brincar, ele impõe o controle dos impulsos, a aceitação das regras. Para Huizinga (1984), o jogo não é uma tarefa imposta, não se liga a interesse matérias imediatos, mas absorve a criança, estabelece limites próprios de tempo e de espaço, cria a ordem e equilibra ritmo com harmonia.

Piaget (2010), destaca quatro etapas que em todos os jogos, podem ser claramente delineadas: 
Os índices, relações ligadas aos significados (uma pegada de um animal);

Os sinais, relações indicadoras de etapas e marcações dos jogos (como apito ou sinais de início, término ou etapas);

Os símbolos são fotos, desenhos, esquemas;

Os signos, elementos de significantes (palavras e números).

Utilizando essas etapas, os jogos estimulam o tato, a audição, o paladar (índices), levam à descoberta de símbolos (pesquisar revistas, recortar, colar, desenhar, dramatizar) e após, exploram símbolos e pressupõem a compreensão de letras e desenhos de objetos correspondentes às palavras (signos).

Durante essas trocas, a criança tem a oportunidade de assumir diversos papéis, experimentar, se colocar no lugar do outro, realizar ações e expressar-se.

\section{O BUMBA MEU BOI}

O Folclore maranhense é variado e diversificado, formado pelo conjunto de danças, festas, manifestações artísticas, lendas, contos, cantigas e histórias que fazem parte da cultura e sabedoria do povo, conservadas pela imitação e tradição popular (NASCIMENTO, 1996).

Entre todas essas manifestações, o bumba meu boi (figura 1) apresenta um grande destaque. Considerado uma das manifestações populares mais expressivas em simbologias, mitos, ritmos, fábulas e magia é também um dos folguedos mais antigos do estado e o mais importante em sua significação plástica e folclórica (NASCIMENTO, 1996).

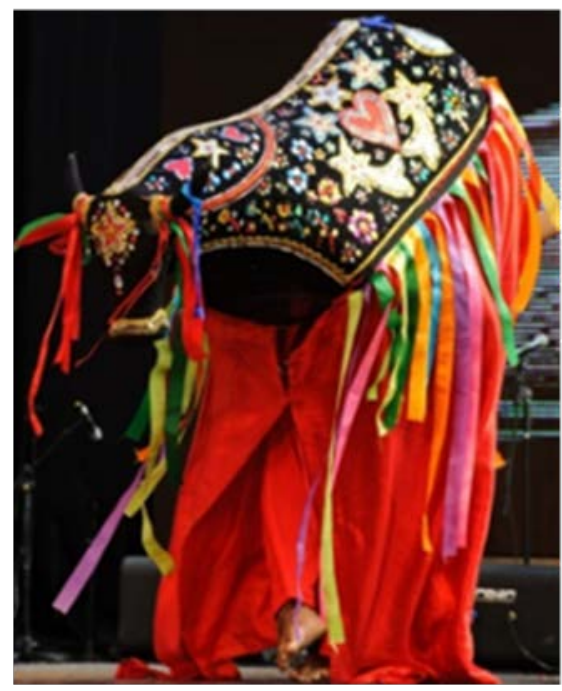

Figura 1 - bumba meu boi.

Fonte: http://www.sarandeiros.com.br/wp-content/gallery/bumba-meu-boi/bumba05.jpg.

O surgimento da brincadeira do bumba meu boi é baseado na lenda do Pai Francisco e a Mãe Catirina. Pai Francisco um vaqueiro escravo que cuida do novilho de estimação de um rico fazendeiro (amo), rouba e mata o boi do patrão, para satisfazer o desejo de sua esposa Catirina, que está gravida, em comer a língua do boi. O amo ao descobrir faz um trato com Nego Chico, se o boi ressuscitar ele será perdoado. Para isso são convocados doutores, padres e feiticeiros, que acabam ressuscitando o 
animal. Com isso, Nego Chico é perdoado e todos comemoram em uma grande festa com comidas, bebidas e cantorias a noite toda. (LIMA, 1994).

Desde estão durante as festas juninas maranhenses todos os arraiais são prestigiados com essa bela apresentação que reúne personagens, instrumentos, vestimentas, brilho e muita alegria.

Dentre muitos personagens da brincadeira do bumba meu boi está o cazumbá (figura 2), um personagem muito misterioso, nem é homem nem é bicho, nem é macho nem é fêmea. De origem africana, representa a fusão dos espíritos dos homens e dos animais que permanecem na terra com os vivos (LIMA, 1994).

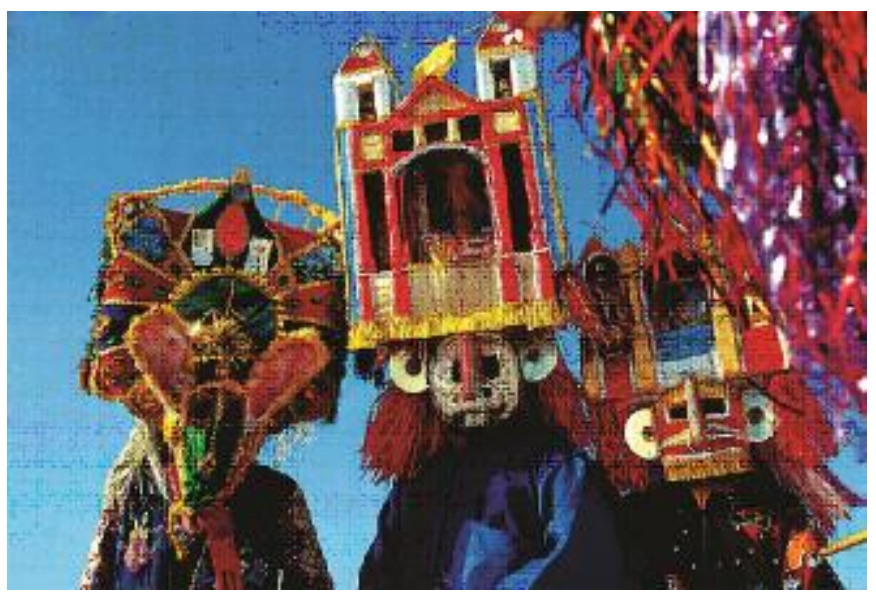

Figura 2 - cazumbá. Fonte:http://imgms.viajeaqui.abril.com.br/70/foto-galeria-materia-620c2.jpeg?1330688050. Acessado em 15/05/2015.

A escolha desse personagem para o nome do Jogo deve-se a fascinação que o cazumbá causa aos telespectadores no momento das apresentações, pois é o responsável pela diversão através do requebrado dos seus quadris, o som do sino que carrega nas mãos e pelos sustos ao público por causa das exóticas máscaras.

\section{JOGO CAZUMBÁ}

\subsection{Metodologia}

Para desenvolvimento do trabalho foi utilizada como referência a metodologia projetual de Bruno Munari (2008) que aponta doze fases para o projeto de design: Problema, Definição do problema, Componentes do problema, Coleta de dados, Criatividade, Materiais/Tecnologia, Experimentação, Modelos, Verificação, Desenho de construção, Solução.

De acordo com Munari (2008), o método de projeto, para o designer, não é absoluto nem definitivo, pode ser modificado caso ele encontre outros valores objetivos que melhorem o processo. Dessa forma adaptou-se a metodologia para o projeto do Jogo Cazumbá.

\subsection{Reconhecimento do problema}

Visando o aprendizado de maneira divertida, a proposta desta pesquisa é desenvolver um projeto de jogo de tabuleiro, intitulado "JOGO CAZUMBÁ: uma 
proposta de jogo de tabuleiro para o ensino do Bumba Meu Boi", com intuito de desenvolver habilidades nas crianças, tornando-as mais participativas no mundo da cultura maranhense. A proposta do jogo cazumbá, por meio do brincar, é ser também, inserido especialmente na Educação Infantil, sendo utilizado durante o planejamento em sala de aula, para que ele aconteça como recurso pedagógico.

\subsubsection{O problema:}

Desenvolver um jogo de tabuleiro lúdico pedagógico com o tema sobre o Bumba Meu Boi, destinado a crianças a partir de oito anos.

\subsubsection{Definição do problema:}

Como já foi visto no corpo desta pesquisa, a cultura popular maranhense, em particular o Bumba Meu Boi, é pouco explorada e difundida na educação, por isso, há necessidade de criar possibilidades de enriquecer o conhecimento sobre o assunto. 0 Bumba Meu Boi, é brincado em quase todo o território maranhense nas festas juninas no Estado, no mês de junho. Ele é um dos mais importantes entre as manifestações folclóricas, no entanto, são escassas as informações para aprendizagem sobre a cultura do mesmo. Após a festa, poucos sabem sobre as brincadeiras e demais particularidades de cada grupo folclórico. Desse modo, surgiu a necessidade da criar um produto que proporcione diversão e interação ao mesmo tempo entre usuários, despertando assim, a curiosidade de conhecer o Bumba Meu Boi. A proposta desse projeto visa à criação de um jogo de tabuleiro pedagógico, com perguntas e respostas, prendas e curingas, que serão chamadas de cartas Cazumbá e terão a função de bônus no jogo.

\subsubsection{Componentes do problema:}

Para solucionar o problema em questão, buscou-se:

- Pesquisar sobre a cultura maranhense com foco na manifestação folclórica do Bumba Meu Boi;

- Pesquisar sobre jogos, seu papel na infância como meio educacional;

\subsection{Processo Criativo}

Na etapa de criação, optou-se em dividir o jogo em 5 partes, denominadas de elementos, personagens, estratégia, layout/arte gráfica e embalagem.

Dessas partes gerou-se propostas (esboços) e depois modelos que passaram por experimentos e verificações.

\subsection{Resultados}

O estudo das etapas anteriores resultou em, 1 tabuleiro (figura 3), 2 dados (figura 4), sendo um com números e outro com personagens, 1 ampulheta (para marcar o tempo) (figura 4), 4 personagens (o Cazumbá, o pai Francisco, o boi, e a mãe Catirina) que servem como pinos (figura 5), 10 cartas prenda (figura 6), 10 cartas Cazumbá (figura 6), 100 cartas de perguntas e respostas (figura 6), 1 impresso com as regras (figura 7) e uma embalagem. 


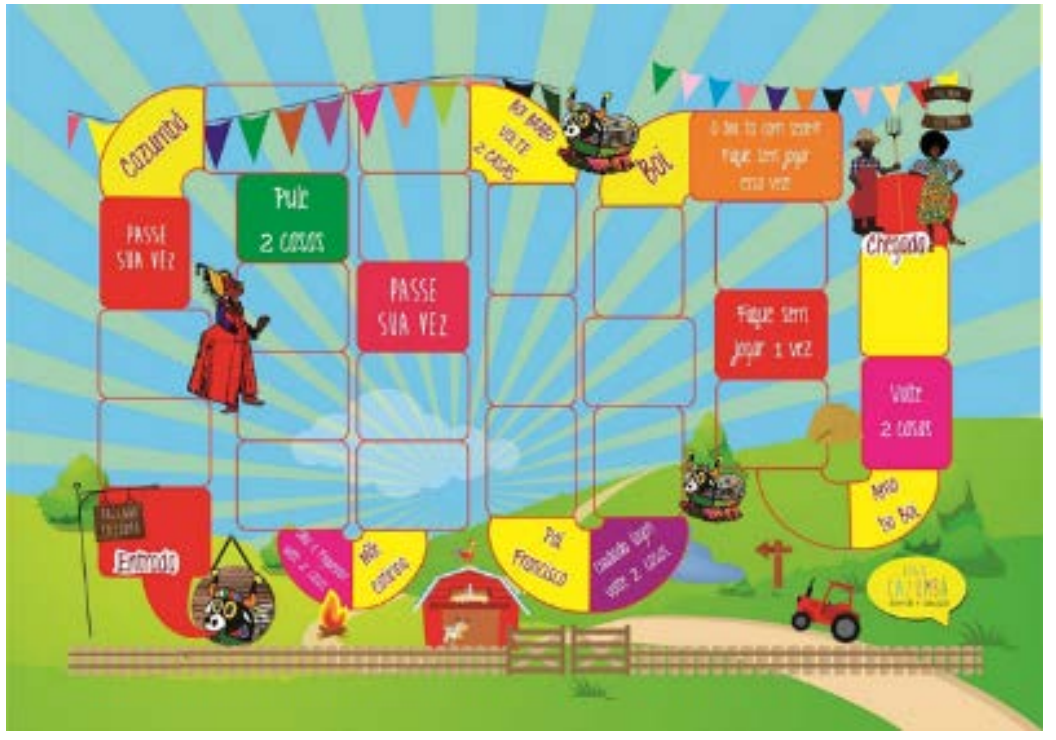

Figura 3 - tabuleiro.

Fonte: Elaborado pelo autor, com base na pesquisa realizada.

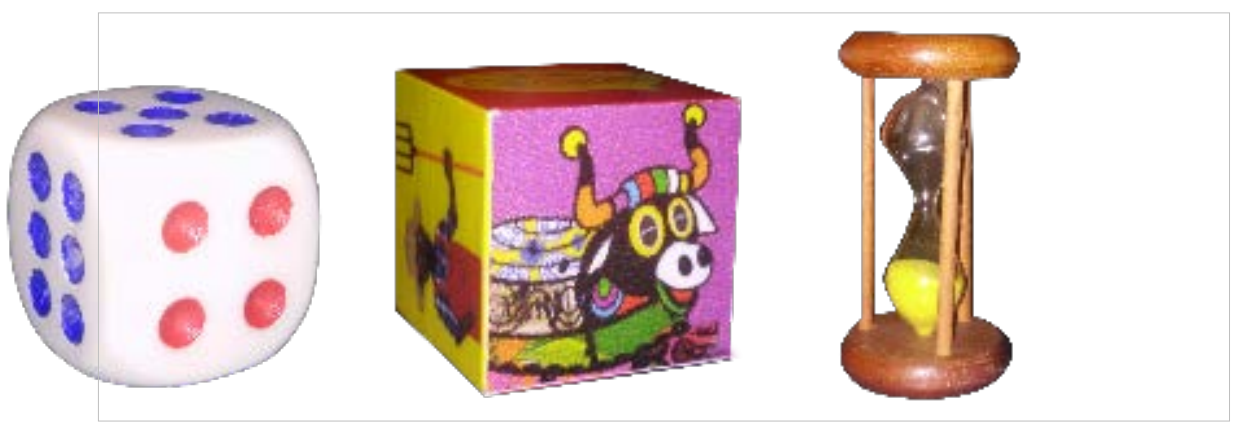

Figura 4 - dado com números, dado com personagens e ampulheta.

Fonte: Elaborado pelo autor, com base na pesquisa realizada.

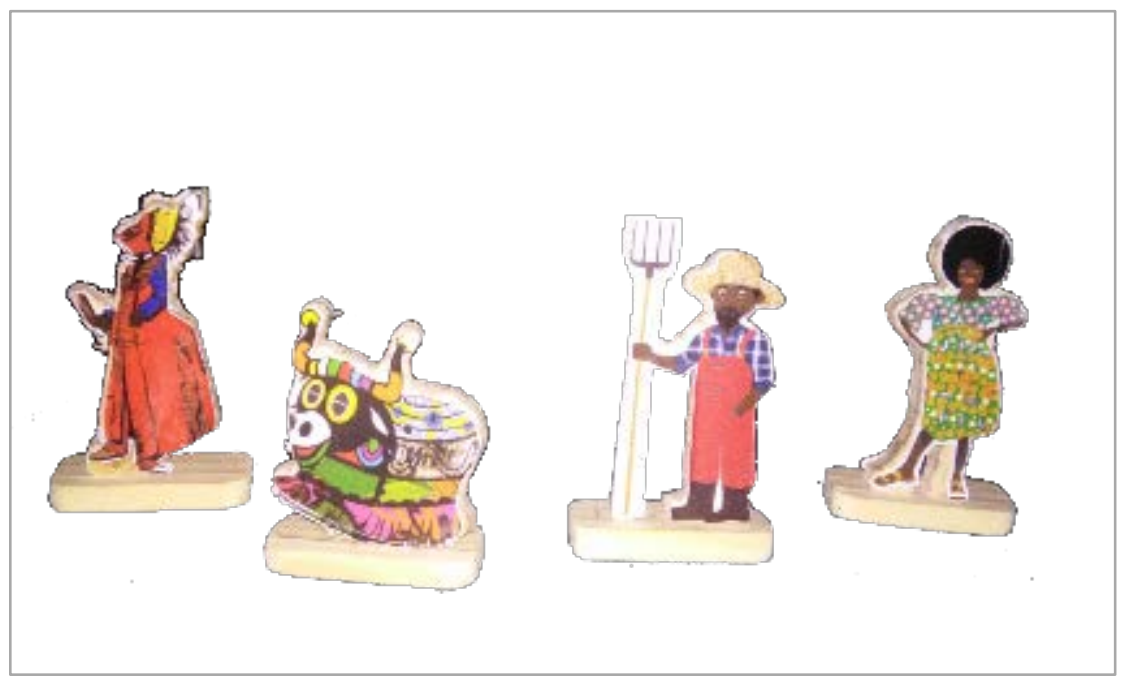

Figura 5 - personagens.

Fonte: Elaborado pelo autor, com base na pesquisa realizada. 

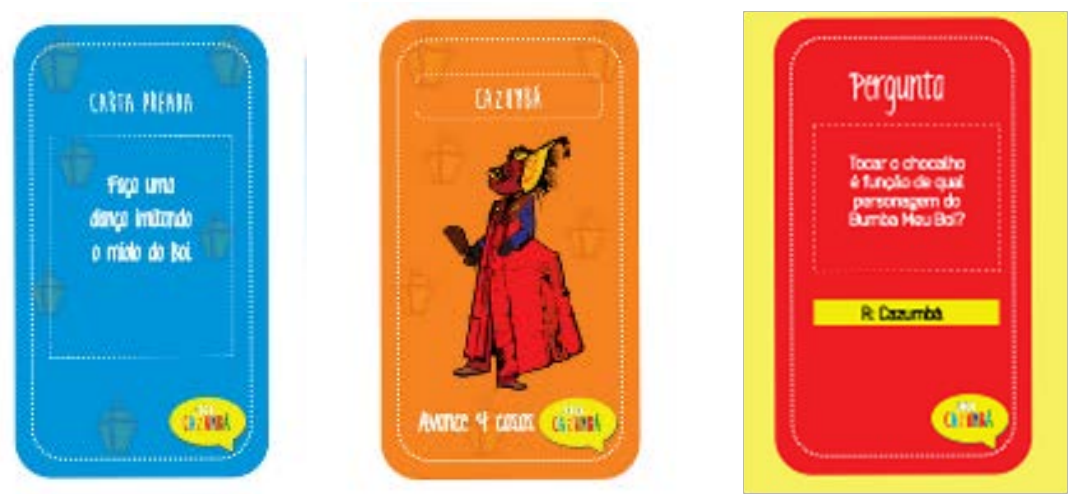

Figura 6 - modelos cartas - prenda, cazumbá, perguntas e respostas.

Fonte: Elaborado pelo autor, com base na pesquisa realizada.

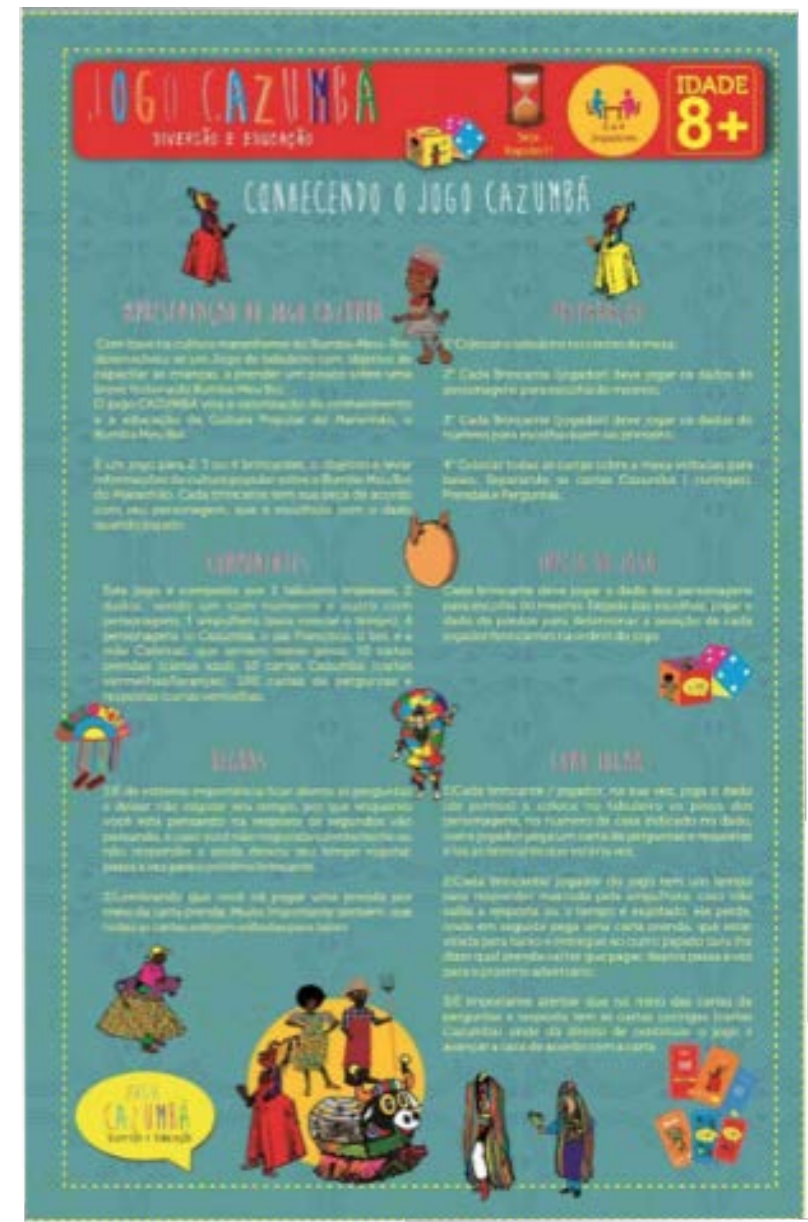

Figura 7- impresso com as regras.

Fonte: Elaborado pelo autor, com base na pesquisa realizada.

\section{- Embalagem do jogo}

Desenvolveu-se a embalagem do Jogo Cazumbá de modo a permitir organização, conformidade e segurança, com o objetivo de provocar uma sensação de apelo emocional e comunicar imediatamente o que tem no conteúdo da embalagem. As imagens a seguir mostram as partes da embalagem (figura 8). 

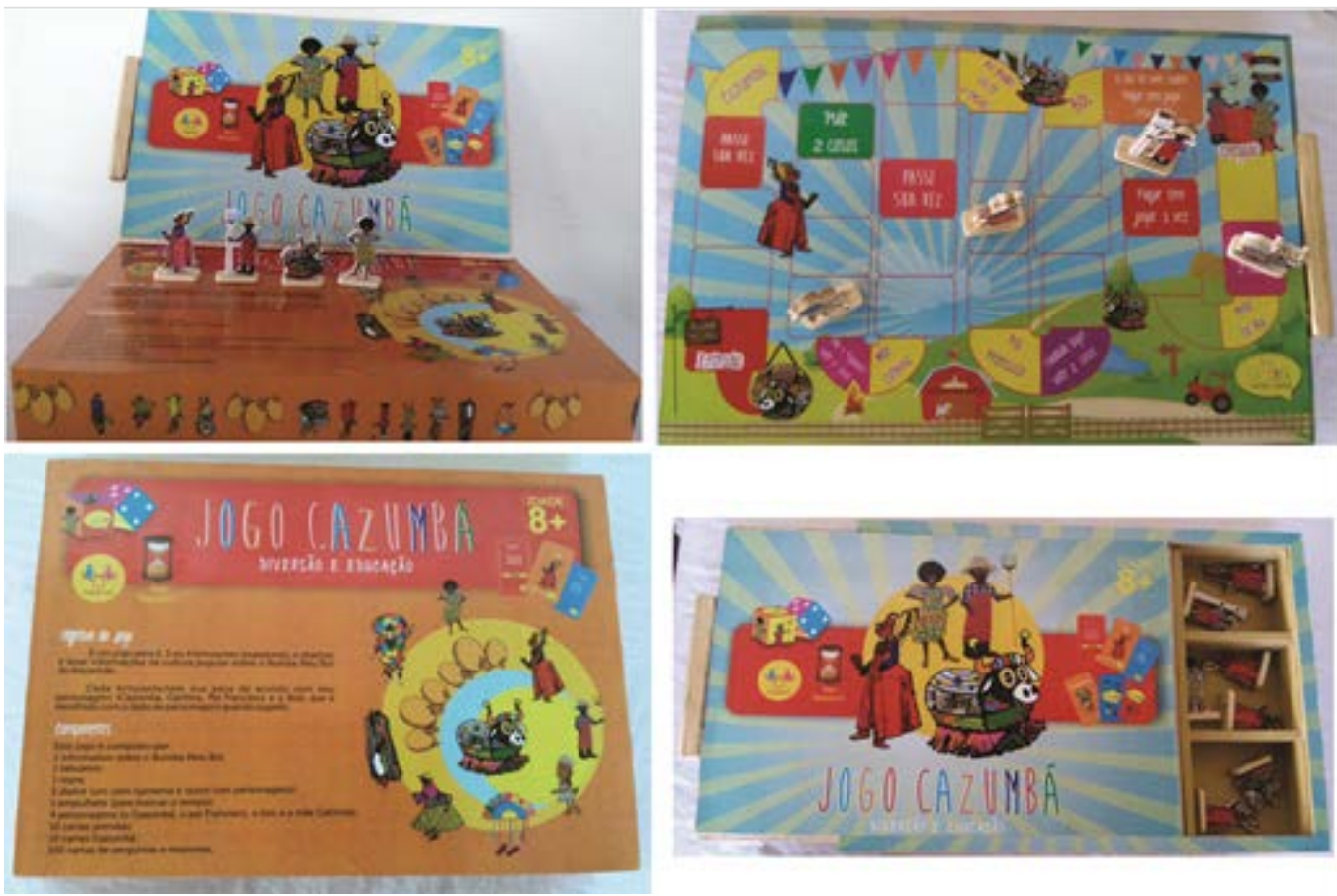

Figura 8 - embalagem

Fonte: Elaborado pelo autor, com base na pesquisa realizada]

\section{- Layout e arte gráfica}

No Jogo Cazumbá, a criação dos layouts, arte gráfica do tabuleiro e dos personagens apresenta característica do Bumba Meu Boi do Maranhão.

Para a paleta de cores, buscou-se imagens relevantes e ricas em cores presentes no Bumba Meu Boi do Maranhão. Assim, definiu-se as cores da paleta a serem utilizadas no projeto (Figura 9).
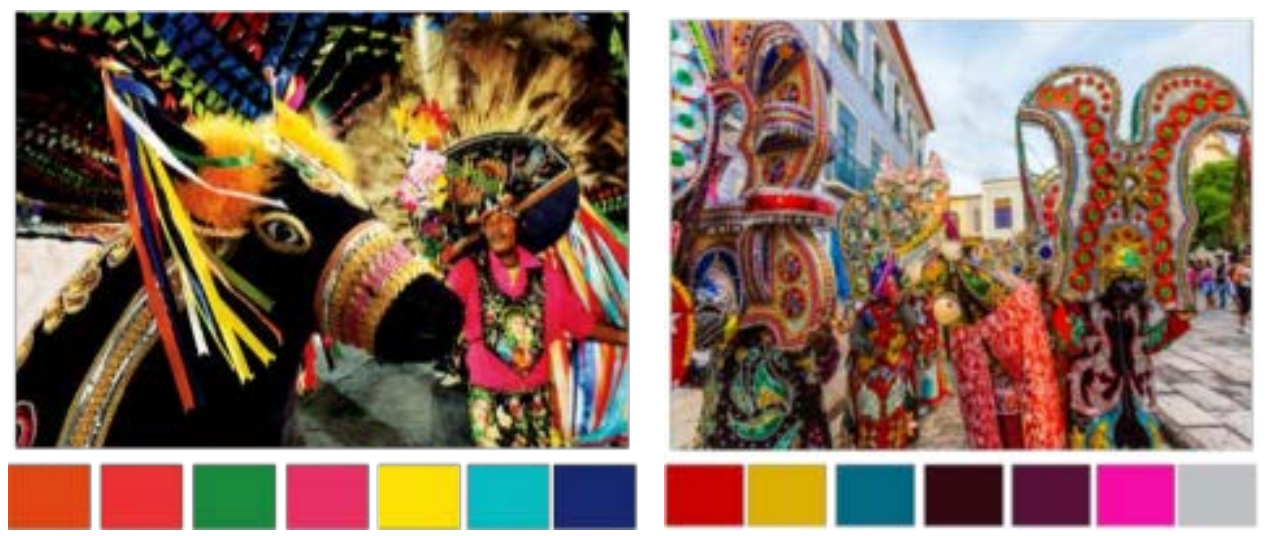

Figura 9: paleta de cores.

Fonte: Elaborado pelo autor, com base na pesquisa realizada.

Para parte gráfica utilizou-se três tipografias: Brain Flower Euro; Kg Love You Through it e Dekar, ambas com peso regular.

A tipografia Brain Flower Euro (figura 10) foi utilizada no nome do jogo, no título das cartas e na embalagem do brinquedo, devido às características formais desta 
fonte, como traços finos e aparente leveza, recordando caligrafia infantil. Logo, ela proporciona proximidade da leitura das cenas na infância com as brincadeiras.

\section{ABCDEFGHIJKLMNOPQRSTUVWXYZ}

Figura 10: tipografia Brain Flower Euro.

Fonte: < http://www.dafont.com/pt/brain-flower.font>.

Empregou-se a tipografia Kg Love You Through it (Figura 11) na palavra "pergunta", impressa na frente das cartas do jogo. Definiu-se esta fonte, pois a ausência de serifa transmite clareza e, sua anatomia orgânica de caráter descontraído dinamiza a palavra em questão.

\section{abcdefghijklmnopqrstuuwxyz.}

Figura 11: tipografias Kg Love You Through..

Fonte:<http://www.1001fonts.com/kg-love-you-through-it-font.html

Como última e terceira proposta de tipografia, definiu-se a Dekar (Figura 12) a ser empregada no corpo das perguntas. O uso desta tipografia foi determinado por suas qualidades formais que garantem boa legibilidade e conforto visual durante a leitura.

\section{abcdefghijklmnopqrstuvwxyz.}

Figura 12: tipografias Dekar, Kg Love You Through, Brain Flower Euro.

Fonte: <http://fontfabric.com/dekar-free-font/>.

\subsection{Materiais e tecnologia}

Para a fabricação do jogo utilizou-se a madeira Araucaria angustifólia, conhecida como pinos. Como acabamento optou-se pelo vinil adesivo com arte gráfica dos personagens.

Optou-se pela madeira pinos por ser uma material de fácil aquisição, podendo ser fabricada com tecnologia local e também por ser uma madeira leve, resistente e de baixo custo. Mas para produção em larga escala outros materiais podem ser utilizado.

\section{CONCLUSÃO}

A presente pesquisa originou-se a partir da ideia de desenvolver um jogo educativo destinado ao público infantil, com a finalidade de levar conhecimento sobre a cultura local de forma lúdica e divertida as crianças. Deste modo, o objetivo proposto para esta pesquisa foi alcançado com êxito. 
Com o auxílio da metodologia de Bruno Munari (2008), desenvolveu-se o Jogo Cazumbá de tabuleiro para o ensino da cultura popular maranhense do Bumba Meu Boi. Sendo o jogo destinado para crianças a partir de oito anos de idade, este público foi escolhido devido à necessidade de transmitir a riqueza da cultura do Maranhão na primeira infância, onde a criança se encontra na fase de desenvolvimento intelectual.

O conhecimento adquirido em todas as etapas desta pesquisa permitiu o desenvolvimento deste projeto, contribuindo para a condução do processo de criação com maior segurança. Portanto, acredita-se que o resultado do projeto é satisfatório e, esta pesquisa poderá inspirar outros projetos nesta mesma linha.

Portanto, é possível concluir que a utilização deste jogo irá proporcionar benefícios aos usuários, devido a suas características de funcionalidade usual e estética, tornando este brinquedo uma importante ferramenta no aprendizado da cultura popular maranhense. Ressaltando-se que o lúdico voltado para as crianças facilita a aprendizagem e o desenvolvimento delas, seja nos aspectos físicos, sociais, culturais, afetivos e cognitivos. Logo, a educação infantil deve considerar o lúdico como parceiro e utilizá-lo para atuar no desenvolvimento e no aprendizado das crianças.

Sendo assim, o Jogo Cazumbá (SOUSA, 2015) é um jogo pedagógico qualificado, que incentiva as crianças a conhecerem melhor a cultura do Bumba Meu Boi com diversão. Cabe ressaltar que o jogo Cazumbá será adaptado e desenvolvido futuramente em jogo virtual.

\section{REFERÊNCIAS}

BRASIL, Secretaria de Educação Básica. Pacto Nacional Pela Alfabetização na Idade Certa. Currículo na Alfabetização: concepções e princípios. Brasília: MEC/SEB, 2012, $48 p$.

CORREA, Gisele Reis. Design e artesanato: um estudo de caso sobre a semente de juçara em São Luís do Maranhão. Dissertação (Mestrado) - Universidade Federal de Pernambuco, Recife, 2010.

EAGLETON, Terry. A ideia de cultura. 2.ed. São Paulo: Unesp, 2011. 208p.

FRIEDMANN, Adriana. Brincar: crescer e aprender- o resgate do jogo infantil. São Paulo. Moderna, 1996.

HUIZINGA, Johan. Homo Ludes. Madri: Alianza/Emecé, 1984.

KISHIMOTO, Tizuko, M. Jogo, Brinquedo, Brincadeira e a Educação. 14 ed. São Paulo, Editora Cortez, 2011.

LARAIA, Roque de Barros. Cultura: um conceito antropológico. 19. ed. Rio de Janeiro: Jorge Zahar, 2006.

LIMA, Francisco José Florêncio. Descobrindo o bumba meu boi, estudo da cultura popular maranhense nas séries do $\mathbf{1}^{\circ}$ grau menor. São Luís: UFMA 1994.

MACHADO, M. M. O brinquedo-sucata e a criança. Edições Loyola, 2003.

MUNARI, Bruno. Das coisas nascem coisas; tradução José Manuel de Vasconcelos. 2 ed. São Paulo. Martins Fontes, 2008. 
NASCIMENTO, Maria Nadir. Terra das Palmeiras: geografia e história do Maranhão. São Paulo: FTD, 1996.

RODRIGUES. Maria Luzia. A CRIANÇA E O BRINCAR. Dissertação de mestrado Universidade Federal Rural Do Rio De Janeiro. Pós-Graduação. 2009.

PIAGET, Jean. A formação do símbolo na criança: imitação, jogo e sonho, imagem e representação. Tradução de Álvaro Cabral e Christiano Monteiro Oiticica, 4 edição, Rio de janeiro: LCT, 2010.

SANTOS, Joaquim Antônio. Bumba-meu-boi: som e movimento. Instituto do Patrimônio Histórico e Artístico Nacional no Maranhão (Iphan - MA). São Luís, 2012.

SILVEIRA, Jacira Cabral da. Infância na Mídia: sujeito, discurso, poderes. (Dissertação de Mestrado) Porto Alegre: FACED/UFRGS, 2000.

SOUSA. Claudia Nayanne Gaspar. JOGO CAZUMBÁ: uma proposta de jogo de tabuleiro para o ensino sobre o Bumba Meu Boi. São Luís, 2015. Monografia do curso de graduação Design - Universidade Federal do Maranhão.

VYGOTSKY, L. S. A formação social da mente. São Paulo: Martins Fontes, 2007. 